\title{
PANDEMIA COMO CATÁSTROFE E ANTÍDOTO: INTERLOCUÇÕES ANTROPOCENAS ENTRE RELIGIÕES DE MATRIZ AFRICANA E ANTROPOLOGIA
}

THE PANDEMIC AS BOTH CATASTROPHE AND ANTIDOTE: ANTHROPOCENE INTERLOCUTIONS BETWEEN AFRICANBASED RELIGIONS AND ANTHROPOLOGY

\section{Marília Kosby}

floorkosby@gmail.com

Bolsista Capes/PRINT de Pós-Doutorado, no Programa de Pós-Graduação em Antropologia Social, Universidade Federal do Rio Grande do Sul. Pesquisadora da Rede Covid-19 Humanidades MCTI.

ORCID: https://orcid.org/0000-0003-1037-5490

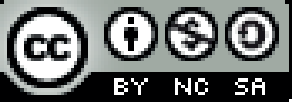

Esta obra está licenciada sob uma licença Creative Commons Attribution-NonCommercial-ShareAlike 4.0 International License.

\section{RESUMO}

Elaborado a partir das pesquisas do Mapeamento das Casas de Religião de Matrizes Africanas no Rio Grande do Sul (Módulo 2) - Pelotas, Rio Grande e Jaguarão, desenvolvidas entre os anos de 2020 e 2021, por demanda do Instituto do Patrimônio Histórico e Artístico Nacional-RS, este artigo é fruto de trabalho de cunho qualitativo, baseado em observação participante e realização de questionários e entrevistas, que buscou esboçar uma cartografia social do campo afrorreligioso no sítio referido. As interlocuções com pais e mães de santo trazidas pelo presente estudo apresentam narrativas dessas pessoas sobre os impactos da pandemia de covid-19, suas possíveis causas e efeitos. Temos, assim, que as casas de religiões de matriz africana trazem em seus fundamentos cosmoecológicos e religiosos premissas que, ao ressoar (ANJOS, 2006) no discurso das ciências humanas a respeito das crises do capitalismo individualista e exploratório, que tão fortemente tem marcado o Antropoceno, este "tempo de catástrofes" (STENGERS, 2015) discursos tais como, por exemplo, o que traz a necessária afirmação de que "a pandemia é sintoma de uma catástrofe muito maior" (SEGATA, 2021) - radicalizam-no, permitindo que possamos enxergar em um dos lados da doença o seu antídoto: a retomada dos laços que compõem uma vida boa.

Palavras-chave: religiões de matriz africana; covid-19; antropoceno; antropologia da saúde; multinaturalismo.

\section{ABSTRACT}

Elaborated from surveys of the Mapping of Afro-Brazilian Places for Religious Practice in Rio Grande do Sul (Module 2) - Pelotas, Rio Gran- 
de, and Jaguarão, developed between 2020 and 2021, by request of the National Historical and Artistic Heritage Institute-RS, this article is the result of qualitative work, based on participant observation, questionnaires, and interviews, which sought to outline social cartography of the Afro-religious field in the aforementioned site. The dialogues with the practitioners brought about by this study present narratives about the impacts of the covid-19 pandemic, its possible causes, and effects. We have, therefore, that African-based religious houses bring in their Cosmo-ecological and religious foundational premises that, when resonating in the discourse of the human sciences regarding the crises of individualistic and exploratory capitalism, which has so strongly marked the Anthropocene, this "time of catastrophes" (STENGERS, 2015) - speeches such as, for example, which brings the necessary statement that "the pandemic is a symptom of a much greater catastrophe" (SEGATA, 2021) - radicalize it, allowing us to see on one side the antidote for the disease: the resumption of the bonds that make up for a good life.

Keywords: Afro-Brazilian religions; covid-19; anthropocene; good life; multinaturalism.

\section{APRESENTAÇÃO}

Este artigo foi elaborado a partir das pesquisas do Mapeamento das Casas de Religião de Matrizes Africanas no Rio Grande do Sul (Módulo 2) - Pelotas, Rio Grande e Jaguarão, realizadas entre os anos de 2020 e 2021, por demanda do Instituto do Patrimônio Histórico e Artístico Nacional-RS. ${ }^{1}$ Trabalho de cunho qualitativo, com metodologia centrada principalmente em observação participante (INGOLD, 2016) e realização de entrevistas e questionários, o Mapeamento (Módulo 2) visitou casas de religiões de matrizes africanas no sítio referido e arredores, seguindo indicações das/os afrorreligiosas/os, conforme foram acontecendo as interlocuções. Os pontos de partida para o estabelecimento dos contatos de campo foram as casas: Comunidade Beneficente Tradicional de Terreiro Caboclo Rompe Mato e Ilê Axé Xangô, dirigida por İyá Gisa de Oxalá (de nação cabinda, em Pelotas), o Ilê Axé Bará Lonan, de Mãe Marli do Bará (de nação jêje-nagô, em Rio Grande) e o Ilê Axé Mãe Nice de Xangô, dirigido por Mãe Nice (de Candomblé Angola, em Jaguarão), por já terem tido relação prévia com processos de patrimonialização de bens culturais referentes às tradições de matriz africana e por participarem de instâncias representativas do Povo de Terreiro, em âmbito municipal e mesmo nacional. As visitas seguiram protocolos sanitários rígidos de controle da transmissão da covid-19, tendo havido a possibilidade das entrevistas serem realizadas de maneira remota. Algumas das interlocuções que compõem este artigo são, portanto, conversas realizadas via aplicativos de mensagens para telefones celulares. 
Um dos objetivos da pesquisa do Mapeamento (Módulo 2) foi a elaboração de um relatório técnico histórico-antropológico, visando subsidiar ações do IPHAN voltadas para a salvaguarda material e imaterial de bens culturais referentes às tradições religiosas de matrizes africanas em Pelotas, Rio Grande e Jaguarão - atentando para as relações com outras regiões com as quais essas cidades mantêm laços de axé. Segundo Vinícius Oliveira

A bibliografia histórica sobre Rio Grande, Pelotas e Jaguarão no século XIX permite pensá-las como cidades negras, na acepção empregada pelo historiador Flávio Gomes (2006), dada a elevada presença de população afrodescendente escravizada, liberta e livre, em grande parte africana. As experiências sociais destes grupos conformaram um leque amplo de configurações, incluindo diversas formas de organização coletiva como os clubes negros, as irmandades religiosas, os quilombos, os zungus e a mobilização coletiva pela alforria. A vivência de suas matrizes religiosas de origem africana pode ser incluída nestes casos, uma vez que guardam uma dimensão coletiva essencial para a sua existência (KOSBY; OLIVEIRA, 2021, p. 36).

O Plano Básico (IPHAN-RS, 2019), em cujas diretrizes a pesquisa assenta sua programática de desenvolvimento, justifica a necessidade da realização do estudo para que sejam elaboradas ações de proteção das manifestações afrorreligiosas contra as violências motivadas por racismo e intolerância religiosa. Alia-se, portanto, à observação participante antropológica a ideia de cartografia social - com base nas proposições de inspiração foucaultiana e deleuziana - no que ela tem de contraposição à cartografia tradicionalmente vinculada às Geografias, aquela bastante interessada em valores matemáticos e estatísticos (PRADO FILHO; TETI, 2013). Em A cartografia como método para as ciências humanas e sociais, estes autores fazem um esboço do que seria o método cartográfico derivado das incorporações das obras de Deleuze e Foucault:

Assim, a cartografia social aqui descrita liga-se aos campos de conhecimento das ciências sociais e humanas e, mais que mapeamento físico, trata de movimentos, relações, jogos de poder, enfrentamentos entre forças, lutas, jogos de verdade, enunciações, modos de objetivação, de subjetivação, de estetização de si mesmo, práticas de resistência e de liberdade. Não se refere a método como proposição de regras, procedimentos ou protocolos de pesquisa, mas, sim, como estratégia de análise crítica e ação política, olhar crítico que acompanha e descreve relações, trajetórias, formações rizomáticas, a composição de dispositivos, apontando linhas de fuga, ruptura e resistência (PRADO FILHO; TETI, 2013, p. 47).

A realização, em plena pandemia de covid-19, de uma pesquisa cuja metodologia prima, em muitas instâncias, por aspectos fenomenológicos das relações estabelecidas no campo, não poderia ignorar os impactos da disseminação avassaladora da doença causada pelo novo 
coronavírus nas vidas e nos modos de narrar de mães e pais de santo responsáveis por casas que são referência para uma "vida boa" para suas comunidades - vida boa essa implicada em um equilíbrio cósmico, que se sustenta, entre muitos fatores, no cuidado com a manutenção de lugares "na natureza", de viventes outros que humanos, ou seja, que expande seu modo de cultivo e seus efeitos para além do que seria um contexto local ou um grupo fechado em si.

O que se verá adiante, no transcorrer deste artigo, são interlocuções entre o trabalho antropológico e as narrativas de pais e mães de santo, que em seus trabalhos cotidianos vivenciaram as transformações nas noções de bem-estar e doença, além de mudanças drásticas nos anseios de quem busca ajuda religiosa, e que apontam causas possíveis para a pandemia e os efeitos desta na necessária dissolução da hegemonia de modos de viver individualistas. A perspectiva situada nas/nos afrorreligiosas/os - e no trabalho de campo antropológico - afetadas/os pela pandemia de covid-19, enquanto operadora das singularizações compositoras deste estudo, é consoante com a ideia de que o fato de uma doença se propagar em escala global não faz dela um fenômeno universal (SEGATA, 2020).

\section{A PANDEMIA COMO UMA FORÇA DA NATUREZA}

Mãe Michele de Oxum, Ialorixá da Sociedade Africana Nossa Senhora da Conceição e Divino Espírito Santo, de nação Cabinda, da cidade de Pelotas, percebe a pandemia, mais especificamente o coronavírus, como "uma força da natureza", só que desconhecida e "de morte" - porque as forças de morte também são forças da natureza. Para a mãe de santo, uma doença grave, disseminada de modo pandêmico, como a covid-19, vem para que "o ser humano volte a se fragilizar, a se sentir frágil pelo sofrimento alheio". Segundo ela, nós, enquanto humanidade, não estávamos nos compadecendo com mais nada e agora somos obrigados a perceber que nossas vidas são coletivas.

Comecemos, então, por apresentar como se configura, para as religiões de matrizes africanas aqui referidas, a noção de natureza. Ao invés de definir "natureza" como uma categoria ontológica de ordem transcendente, que perpassa certos domínios da vida e determinados fenômenos, na cosmovisão afrorreligiosa tem-se natureza como algo muito concreto, no sentido de compor com todos aqueles corpos e modos de estar vivo singularizados, que independem das ações humanas para existirem, se perpetuarem, se regenerarem. A expressão na natureza - quando se diz, por exemplo, que se precisa despachar um serviço na natureza ou que vai haver um batuque na natureza - nos leva a compreender essa noção, digamos, mais fenomenológica, da natureza como "[...] lugar concreto onde coisas acontecem ou podem acontecer" (SANSI-ROCA apud BARBOSA NETO, 2012, p. 142, tradução minha). Sansi-Roca, nesta citação feita em nota na tese A máquina do mundo: 
variações sobre o politeísmo em coletivos afro-brasileiros, de Edgar Barbosa Neto, se refere diretamente às celebrações e rituais realizados na natureza (no mato, na beira da praia, na cascata, por exemplo), que não implicariam em um tipo de adoração a um ideal abstrato de natureza, mas na confirmação dessa mútua participação entre deuses, humanos e a vida da/na terra.

Acrescenta-se a esta última assertiva que o que se está tratando por concretude aqui implica o cosmos visível e invisível. As forças que não vemos, mas nos afetam, afetam o mundo, causam efeitos transformadores, não estão alocadas em um plano puramente abstrato. É como se essas duas noções também se implicassem mutuamente: no material há sempre algo que não podemos perceber com os olhos; do mesmo modo, o axé, as energias espirituais são canalizadas por corpos materiais e se manifestam através deles.

Veja-se o que disse Pai Diamantino, pai de santo de uma casa de nação Cabinda, em Pelotas, para Kosby:

Então dizem: "vocês idolatram todos os deuses". Nós dividimos deus em forma de natureza, em forma de orixá. Na verdade é um deus só. Tu entendeste? Só que se eu quiser falar com deus em forma de Iansã, eu vejo o vento [...] Para mim, deus está no vento (KOSBY, 2009, p. 45).

$\mathrm{Na}$ etnografia de Isabel Campos, a respeito da Festa de Iemanjá do Barro Duro, aparecem relatos de afrorreligiosos relacionando a importância da festa e dos acampamentos das casas de religião na mata da orla da laguna dos Patos, com a possibilidade de se relacionar com os orixás na natureza. Segue-se o relato de uma interlocutora:

[...] é aquela energia toda que tu pega do orixá daí, da mata, do mar, tu junta energia do mar, água, vento, então aquilo pra gente é importante. Como é que eu vou te dizer, mal comparando, tu recarrega as baterias, sai inteira, que é muito bom [Entrevista realizada com Maria Ochoa, em 4 de novembro de 2014] (apud CAMPOS, 2015, p. 180).

Mãe Maria Elaine de Iemanjá, Ialorixá do Ilê de Iemanjá Boci e Oxalá (nação Jêje com Ijexá), em Pelotas, define natureza como o ambiente em que estamos implicados, do qual é impossível tentarmos nos desengajar sem sofrer consequências devastadoras, pois está também implicada no que somos. Ao referir-se a desastres ambientais, como queimadas e poluição das águas, e relacionando a pandemia de covid-19 às respostas que a natureza dá às ações destrutivas humanas, a mãe de santo afirma que nós (os seres humanos) precisamos cuidar da natureza para garantir a nossa sobrevivência e não a dela - pois esta está garantida, nas palavras de Mãe Maria Elaine: "a natureza vai sempre se regenerar". Mas nós não fazemos parte dessa natureza? Por que não nos regeneraríamos também? Para Mãe Maria Elaine, o princípio fundamental do africanismo é a busca pela confirmação de nossa "comunhão com a natureza", já que os seres humanos são parte desta, mas insistem em tentar rom- 
per essa ligação, criar modos de vida que são motores para a morte, a aniquilação. A busca pelo equilíbrio se dá no sentido de a humanidade (alguma humanidade) conseguir sobreviver à destruição que impõe a si mesma, quando ignora as respostas do ambiente à destruição. Destruição à qual inúmeras espécies e modos de viver outros que humanos irão escapar e se regenerarão, e à qual os humanos sucumbirão. Assim, temos que: menos do que responsáveis pela vida da terra, estamos sendo responsáveis pela extinção de nossa espécie.

Em suma, nessa perspectiva, estamos em um engajamento mútuo com o mundo, nós estamos impactando e sendo impactados pela terra. Não há como nos colocarmos no plano do social ou do cultural, como portadores de excepcionalidades, que fariam com que nos distanciássemos progressivamente do domínio da natureza, atitude epistemológica característica de cosmovisões que privilegiam o paradigma ontológico naturalista ${ }^{2}$. O asfalto, o concreto, as redes sociais virtuais, são tecnologias criadas por seres humanos, mas não podem nos levar a crer que não estamos deixando marcas na superfície da terra. Quando a rua da casa de Mãe Marli do Bará Lonan era calçada com paralelepípedos, a água de seus ecós, ao ser despachada ali, ia direto para o seu destino, a terra, absorvida pelos vãos entre uma pedra e outra; depois que a rua foi asfaltada, o chão ficou como que impermeável e a mãe de santo se vê esperando que a água evapore para se juntar novamente à natureza. Assim, às vezes despacha na praça próxima ao terreiro.

Aqui, cabe lembrar a atenção de Pai Cristiano do Ogum, babalorixá do Reino de Ogum e Cacique Pena Dourada, da nação Cabinda, de Pelotas, em depositar os axés direto no chão - despejar o líquido das bebidas e levar consigo as garrafas, tirar o plástico que envolve as balas pois “o orixá é natureza”. As águas que compõem os axés, os ecós, águas de quartinhas e bebidas, vão direto no solo e por este são absorvidas. Nos despachos de Pai Cristiano do Ogum não são usadas bandejas ou copos de plástico, nem garrafas ou caixas de fósforo - para o pai de santo, do despacho de uma vela, o orixá ou a entidade aproveitam só a luz da chama, portanto, não faz sentido despachar as velas na embalagem. Quando o despacho envolve animais sacralizados, buscam-se matos, a praia ou lugares bem isolados, de preferência onde não houver asfalto, pois “o orixá é chão" e o asfalto demora muito para absorver os axés.

Pai Cristiano manifesta uma preocupação que é praticamente unânime entre todas as mães e pais de santo entrevistados: de que aquilo que se está entregando de volta para a natureza, porque dela foi tirado, possa se reintegrar a ela. Em um vídeo documental, disponibilizado para esta pesquisa pelas casas de Mãe Nara Louro do Xapanã (Centro Africano Pai Xapanã, nação Jêje com Ijexá, em Pelotas) e Mãe Maria Elaine de Iemanjá, o africanismo é descrito como uma religião cotidiana professada por famílias comprometidas com o ciclo vital do universo. Nas palavras de Mãe Nara, no mesmo vídeo, tal organicidade, vivenciada em um ci- 
clo vital mútuo, está compreendida na afirmação de que "o nosso corpo só absorveria aquilo que a natureza absorve".

Mãe Nara do Xapanã cita o itan "tu não comes o que te machuca" para explicar o porquê de não despachar oferendas em garrafas, latas, objetos metálicos, que agridem a natureza. Por isso a preocupação generalizada em propagar a prática de despachos ecologicamente harmônicas. Para sermos mais precisos: "cosmoecologicamente" harmônicos (DESPRET, 2016). Com o conceito de cosmoecologia, portanto, dá-se ênfase à implicação mútua das origens, caminhos e destinos de ancestrais, orixás, pretos velhos, caboclos, exus, ervas, rios, matos, árvores, pedras, humanos, aves, cabras, alimentos e leva-se adiante a ideia de que, para as tradições de matrizes africanas, um desequilíbrio ecológico é também cosmológico - assim como uma instabilidade nos arranjos cosmológicos pode ser atenuada ou resolvida através de trocas ecológicas mais equilibradas (KOSBY, 2021). E tal equilíbrio entre ecologia e cosmologia depende de operações rituais complexamente sutis: onde, na natureza, tal orixá ou tal entidade come? O que come? Como come?

Um jeito da natureza comer as oferendas é pela boca de humanos e de animais não humanos. Pai Cristiano do Ogum, por exemplo, despacha tudo direto no chão, sobre folhas, e logo em seguida de quando a oferenda ou demais despachos são largados, as pombas, os cachorros comem o que ali foi depositado, o que é uma maneira da natureza receber aquele axé. Mãe Ema do Xangô, Ialorixá do Ilê Elaká, casa de nação Jêje-nagô, de Rio Grande, também é contrária ao despacho de bebidas dentro das garrafas, velas nas embalagens, bandejas de plástico. Para ela, as bebidas devem ser despejadas direto no solo e as bandejas devem ser forradas com folhas de mamona, bananeira ou embira, para que as oferendas sejam depositas sobre estas, diretamente no chão, e as bandejas levadas de volta para o terreiro para serem reutilizadas apenas como suporte. A exceção é quando as oferendas são feitas em espaços com circulação de pessoas, por exemplo: brinquedos, balas e bombons colocados em oferendas nas praças, são deixados com embalagem, pois "as crianças pegam”. Refrigerantes e bebidas deixadas em lugares onde há muitas pessoas em situação social de vulnerabilidade são deixadas nas garrafas, para que sejam consumidas pelos moradores dos arredores. $\mathrm{O}$ mesmo acontece com as comidas e frutas, que são deixadas nas bandejas, nessas situações. Segundo a mãe de santo, o intuito da oferenda é mesmo que alguém pegue, esse é um jeito de chegar ao seu destino. Por isso, ela não deixa as oferendas mofarem no quarto de santo para depois despachá-las, prefere levá-las frescas para a natureza, já que "tem muita gente com fome".

Em entrevista ao historiador Marcelo Studinski, pesquisador local do Mapeamento (Módulo 2), o Cacique Gerônimo, do Centro Espírita Umbandista Seguidores do Caboclo Arruda, em Rio Grande, relata que parou de realizar oferendas em alguns locais da cidade do Rio Grande 
devido ao acúmulo de lixo, como a orla da rua Henrique Pancada (laguna dos Patos) e o portão do cemitério local, pela avenida $1^{\circ}$ de Maio. Gerônimo considera que "oferenda não pode ser nem se misturar com lixo", e que, "lugar que tem lixo ou provoca lixo deixa de ser um lugar sagrado". Por isso, prefere lugares limpos, como a praia do Cassino e o locais mencionados, sempre evitando fazer suas oferendas de modo nocivo ao meio ambiente.

Pai Chiquito, babalorixá da Casa da Nação Reino De Oxum e Xangô, de nação Cabinda, em Jaguarão, também não faz oferendas com garrafas, plásticos ou qualquer elemento que não seja comestível ou biodegradável - considera o fato de "não saber despachar" um dos hábitos do pessoal de religião que contribui para a deturpação de sua própria tradição. Nesse sentido, Mãe Maria Elaine sustenta a importância de se organizarem políticas educativas entre os terreiros, para a orientação das casas recém-abertas, principalmente no que tange a essa questão dos despachos dos animais e de oferendas. Ela lamenta não haver uma fiscalização interna, por parte das entidades representativas das casas de religião, que se responsabilize por gerenciar a conduta das casas nesse sentido.

Enfim, o preceito que atravessa essa sofisticada inversão do paradigma naturalista desloca a noção de natureza como um conjunto de "recursos naturais" a serem explorados, ou finitos a serem preservados, representada por uma mãe dadivosa e terna, sempre na iminência de ser martirizada pelos filhos. A terra "está comendo muita gente", lamenta Mãe Maria Elaine; "a terra vai comer muita gente", anunciou o Pai Xangô do falecido Pai Nilo, prevendo, pouco antes do falecimento de seu filho, "a peste" que nos acomete agora. A terra aqui é o planeta e o nome de sua carne, como já disse o poeta. A terra, como esse complexo concreto e vivo, aparece como corpo em que a natureza acontece, numa lógica que poderia ser inscrita naquilo que a filósofa belga Isabelle Stengers (2015) chama de "éticas ecocêntricas", éticas não submissas à ânsia pelo progresso e ao disparate consumista do capitalismo, que precisa nos desengajar da terra para se consumar enquanto glória e triunfo da razão humana.

Em No tempo das catástrofes, Stengers desenvolve a ideia de que, nessas éticas ecocêntricas, as relações estão pautadas pela implicação entre nossas ações e a resposta de $\mathrm{Gaia}^{3}$; resposta que, em modo de catástrofes de toda ordem, é caracterizada pela autora como a "intrusão" de Gaia. A autora vai chamar de Gaia este ser autorregulado como qualquer ser vivo - que se reajusta, por exemplo, alterando seus padrões termo-climáticos quando aumentamos a emissão de gases de efeito estufa. Esse reajuste de Gaia é a vida e é a manutenção da vida de Gaia, que não é, necessariamente, a manutenção da nossa espécie. Ou seja, Gaia reequilibra-se em ressonância com a sobrevivência de outros seres, que não necessariamente os humanos. 
Em um colóquio realizado no ano de 2014, no Rio de Janeiro ${ }^{4}$, defendeu-se a ideia de que essa potência, ora chamada Gaia, teria inúmeros outros nomes. Nas tradições de matrizes africanas há também mitos e deuses para a terra, potências de vida e bênçãos, divindades fundadoras, protagonistas de mitos da criação, por um lado, e de outro capazes de implacáveis respostas para romper os ímpetos de onipotência destrutiva de suas criaturas mais controversas, os seres humanos. São divindades e mitos que tecem narrativas compositoras e compostas por éticas ecocentradas. Para ficarmos com aqueles mais diretamente atrelados à relação com a terra, vejamos o culto a Nanã, suas origens e derivações:

Nanã é guardiã do saber ancestral e participa com outros orixás do panteão da Terra, do qual uma antiga divindade, Onilé, ainda recebe em velhos candomblés uma cantiga ou outra em ritos de louvação dos antepassados fundadores da religião. Onilé, a Mãe Terra, é a senhora do planeta em que vivemos. As atribuições de Onilé foram redistribuídas entre Nanã e outros orixás que muitos seguidores consideram filhos seus. Nanã é a dona da lama que existe no fundo dos lagos e com a qual foi modelado o ser humano. É considerada o orixá mais velho do panteão na América (PRANDI, 2001, p. 20).

No Candomblé Angola de İyá Cota da Oxum, em Rio Grande, o Reino de Iemanjá Candomblé de Xangô e Oxum - antigo terreiro de Pai Nilo do Xangô - cultua-se Nanã Buruku, enquanto orixá individual e ancestral. É o que relata o filho de Mãe Cota, Marcelo de Xangô (Marcelo Studinski):

Para nós, Nanã é a grande Agbá (mais velha), a Senhora Ancestral de todos os seres humanos. Seu culto é vinculado à saúde, à fertilidade, à vida e à própria ancestralidade e, por isso, também é cultuada nos rituais de axexê, no igbalé e afins. No candomblé não utilizamos nada de metal no culto a Nanã. Suas cores são o branco (que representa a ancestralidade) e o roxo/lilás (que representa a fertilidade, pois está vinculada à água). Nanã, para nós, é representada nas águas paradas de lagos, brejos, pois ela é o barro (água + terra) (MARCELO DE XANGÔ, comunicação pessoal com a autora, em junho de 2021).

No Batuque de nação Jêje do Reino de Iansã e Juremita, em Rio Grande, atualmente dirigido por Mãe Jane do Bará, filha mais velha e sucessora da falecida Mãe Neli da Oiá, Nanã Buruku está na escala de Iemanjá, é como se fosse uma variação desta orixá. Na nação Jêje, o orixá mais diretamente ligado à Terra, enquanto chão, é Xapanã. Segundo Eneida de Oxalá, irmã de Mãe Jane e tamboreira do Reino de Iansã e Juremita, Xapanã é o dono da saúde e da doença, do povo que habita a Terra, "que pisa na terra" - sempre lembrando que os orixás nunca trabalham sozinhos, então Xapanã teria uma maior liderança nesse domínio, mas contaria com outros santos para regulá-lo. Assim, na casa de Eneida, e em outras de mesma nação, Xapanã trabalha junto com Ossanha, que é médico e conhecedor das ervas de cura, dos brotos, raízes, 
folhas: Ossanha busca-as e as entrega a Xapanã, que "passa o remédio nas doenças". Segundo Eneida, Xapanã é o dono da Terra porque "governa as coisas vivas da Terra", este orixá "era o grande pajé das tribos antigas", "o dono do chão". Porque a doença também vem da Terra. E quando vem em escala pandêmica, segundo ela, faz com que a medicina evolua, faça novas descobertas, volte-se para seu sentido mais urgente; uma pandemia também religa as pessoas, seja em oração, seja em fé. Por isso, é a Xapanã que se agradece por poder "acordar e pôr o pé no chão, na Terra".

Tim Ingold (2016) conversa harmonicamente com esses preceitos, ao observar que o modo moderno de habitar, que preconiza a metrópole, lida com o chão como uma superfície onde não se deve deixar rastros - daí o fascínio moderno pelo asfalto, pelo concreto. Assim, a superfície onde se pode pisar é aquela capaz de parecer intocada por nossa presença. Os rastros deixamos quando fazemos atalhos, pisando nos canteiros, nas matas, no barro, desafiando a autoridade que pré-mapeia nossos passos. Acontece que não somos só nós que deixamos marcas no caminho, mas somos também marcados por este. Como então a modernidade tratou de lidar com as interferências do chão na mente sedentária, aquela cuja racionalidade seria privilegiada pelo repouso? $\mathrm{O}$ autor nos responde:

É como se, para os habitantes da metrópole, o mundo de seus pensamentos, seus sonhos e suas relações com os outros flutuasse como uma miragem acima da estrada em que pisam em sua vida material real (INGOLD, 2016, p. 78).

Em termos mais específicos, para a discussão que desenvolvemos aqui nos importa levar o mais adiante possível a premissa de que "os orixás respondem na natureza” e que sem natureza não há orixá. Mas veja-se novamente que estarmos "em comunhão" com a natureza, para as religiões de matrizes africanas, não implica em abdicarmos daquilo que, numa visão naturalista, estaria classificado como "cultural" ou "social": importa perceber que orixás, humanos, rios, animais, a terra, compartilham socialidades. Nesse sentido, José Carlos Gomes dos Anjos descreve como a cosmovisão afrorreligiosa opera de modo nômade, proliferando múltiplas perspectivas nos corpos, contrariando a lógica moderna e naturalista:

Pedras com perspectivas. Animais e vegetais sacralizados. Santidades que se alternam. Raças que percorrem outras raças. Esse é o mundo dos terreiros. No sentido que Viveiros de Castro (2002) retoma de Latour poderíamos falar aqui de um multinaturalismo que em lugar de multiplicar as culturas multiplica as perspectivas no interior dos corpos. Aqui os corpos não têm raças, raças são perspectivas que circulam por uma multiplicidade de corpos. Uma multiplicidade de perspectivas gera uma multiplicidade de mundos nos quais se destacam conceitos que singularizam esses mundos. [...] A sacralização de determinadas dimensões da 
natureza está correlacionada a um processo de circulação de perspectivas por corpos (ANJOS, 2006, p. 119).

İyá Gisa nos conta que prefere não fazer oferendas para Oxum no arroio Pelotas porque este curso de água traz memórias muito sofridas dos tempos da escravidão. Para a ialorixá, largar uma oferenda pedindo doçura, alegria de viver, abundância - e mais tudo que se pede a Mãe Oxum - requer que se esteja com o coração alegre, mas num lugar onde a memória é tão dolorosa, "até a natureza fica triste". E quando alguém está triste, é muito difícil dar um bom axé. A natureza não responde tão bem. ${ }^{5}$

Desde que começou a pandemia, quando Mãe Michele de Oxum joga búzios para alguém, os orixás respondem para que seja feito um serviço de fortalecimento do organismo da pessoa para segurar o espírito no corpo - como se o orixá não estivesse garantido a vida de quem tem covid-19. Conforme vai-se fazendo o serviço, às vezes a pessoa vai melhorando. O orixá não garante porque o coronavírus "é uma força da natureza", não existindo um tratamento para o vírus. É diferente de alguém estar com enfisema pulmonar: jogam-se os búzios e o orixá vai dizer "faz uma troca de pulmões" - sabe-se que tem tratamento e tem um trabalho específico para esse enfisema. Para a covid-19 não existe um trabalho específico, pois pode pegar nos rins, nos pulmões, no coração. Então, o orixá manda que se fortaleça o organismo para segurar o espírito no corpo, já que quando o corpo está fraco "o espírito se vai". Mãe Michele conta que tem sido raro fazer um serviço que não seja para a saúde, não só para covid-19: pessoas enfartando, com depressão, com síndrome do pânico, com ansiedade, com doenças nervosas afetando estômago e fígado, dentre outros problemas de saúde. ${ }^{6}$ A Ialorixá conta que sempre trabalhou para questões em geral (amor, saúde, dinheiro), mas agora “o geral não existe mais porque as pessoas só adoecem!”. É só jogar os búzios e a primeira questão que surge é o orixá zelando pela vida da pessoa, mandando tomar cuidado. É raro alguém ligar e os búzios dizerem que a pessoa está com problema no casamento, por exemplo - desde que começou a pandemia, Mãe Michele fez só dois serviços para amor, antes era esse o tipo de trabalho que mais se fazia. Ela relata: "É só coisa ruim, ou tu estás desempregado, ou estás morrendo. Ninguém vem querendo arrumar casamento ou tomar banho de pomba-gira..

Mãe Michele diz que essa força da natureza, que é a pandemia, é uma força desconhecida e de morte. Veio para fazer uma limpeza espiritual na Terra. Quem está ficando, está em teste, teste para ver até onde vai nossa capacidade de aceitar os valores da vida. Segundo a Ialorixá, o ser humano perdeu todos os valores, inclusive o valor pela terra, ele não tem amor pela terra. Dar valor a terra, na concepção de Mãe Michele, é se preocupar com a natureza e com as demais pessoas, dar valor à vida: "e a vida é tudo, é fogo, terra, água, ar. O orixá é vida, se destruirmos as florestas, os orixás vão parar de responder para a gente porque eles são forças da natureza. 
Toda vez que se polui um rio, se está matando um pouco a Mãe Oxum”. Para Mãe Michele, se a Mãe Oxum é a mãe do ouro, não é do ouro do garimpo, é do ouro da vida, que é a coisa mais preciosa que se tem. Perder o valor pela vida é não se fragilizar mais com a fome do outro, com o frio do outro, com o abandono. Nas suas palavras: "A doença veio para nos fragilizar, quem não se fragilizar não vai aprender nada".

Desde que começou a pandemia, Pai Flávio do Xangô, babalorixá do Abassá Africano de Xangô e C.E.U. Xangô das Matas (de nação Cabinda, em Pelotas), atendeu vários clientes da cidade de Bagé, que estavam entubados na UTI por covid-19, e todos sobreviveram. O babalorixá se diz perplexo com a alta procura de clientes com covid-19, buscando ajuda. Ele conta que praticamente só tem feito trabalhos religiosos para esse fim - chegou a atender uma família inteira, cujos membros estavam todos entubados. Atendeu também um médico de Santa Catarina, filho de um filho de santo seu, e conseguiu ajudá-lo a sair da UTI de covid-19. O trabalho é feito em uma roupa usada pelo doente. Pai Flávio diz que sente falta do tempo em que a principal demanda era por serviços religiosos para questões de amor, como busca por casamento, ou pela resolução de briga de namorados. Ele conta que esse período de pandemia é um momento de muita cobrança, em que os orixás estão pedindo socorro, por causa da destruição da natureza, por desmatamentos, por poluição. Segundo o pai de santo, está tudo desregulado, e o sagrado da afrorreligiosidade é da natureza. Por isso, ele atenta muito para como faz as oferendas, deixando na natureza só aquilo que é biodegradável. Não usa bandejas, nem papelotes, nem papéis coloridos, plástico, só folha de mamona. Pai Flávio conta que a própria vizinhança regula quem faz despachos "ecológicos" e quem "suja a cidade". Ele costuma trabalhar com Ossanha, no mato do Santo Antônio, na praia do Laranjal, para questões de saúde. O mato do Laranjal é especial porque fica perto da água e porque possui figueiras muito antigas, árvores consideradas "de raiz". Pai Flávio admira-se: “Com toda aquela poluição, o nosso sagrado ainda responde!”. Na mata também trabalha com Ogum e Xapanã.

Já Mãe Gilmara da Iemanjá, Ialorixá do Templo Africano Ilê Iemanjá Naê, de nação Jêje com Oió, em Pelotas, relata que, a partir da pandemia, os clientes passaram a procurá-la, principalmente, por problemas financeiros e de saúde. Ela conta que muita gente perdeu emprego, muita gente teve que entregar casas de aluguel e morar de favor na casa de outras pessoas. Relata que muitas pessoas começaram a passar necessidade (fome, doença, desemprego, violência) pela primeira vez na vida, pessoas que nunca imaginaram que iam passar por isso. Ela conta que esse fator de desestabilização da vida material tem abalado seus consulentes psicológica e espiritualmente. Um fenômeno que aumentou muito, no caso das pessoas que batem à porta do terreiro pedindo ajuda, é a violência contra as mulheres, muito por conta de estarem os maridos desempregados e passando os dias em casa. 
A pandemia é um alerta para os seres humanos, segundo Baba Fernando de Oiá, pai de santo do Ilê Axé Congregação Filhos de Oiá, casa de nação cabinda, em Pelotas. Não é um castigo, é um alerta para que o ser humano tenha empatia pela dor do outro. Se isso não acontecer, pode acontecer algo pior, como uma epidemia vinda da água. A ganância é a causa da pandemia. Segundo o pai de santo, a pandemia ter a ver com Deus, que, na versão afrorreligiosa, é a natureza. Ele diz: "Eu sou filho da Afefé, que é o vento. Pai Juliano é filho das águas doces, de Mãe Oxum”. Deus é a fauna e a flora e quem está degradando é o bicho homem.

\section{MAIS ALGUNS FUNDAMENTOS PARA UMA VIDA BOA}

Como se pode ver, a busca por um equilíbrio cósmico implica o conhecimento das múltiplas perspectivas que criam e dão sentido aos mundos. Observamos que o axé tem a natureza como fonte de energização e operadora de trocas. Mas ainda não nos detivemos muito em uma questão tão importante quanto a canalização do axé: sua circulação, sua necessidade de se espalhar, como realização da potência de vida de seus cultuadores e propagadores. Pais e mães de santo já falecidos são lembrados saudosamente menos por julgamentos morais de valoração positiva do que pelas memórias do quanto conseguiam criar, através de si, um ambiente de acolhimento e agregador: seja pelo simples bom humor, ou pela disposição a fazer churrascos com as/os filhas/os e amigos, seja pela eficácia de seus passes e benzeduras, ou pela disposição em trazer a religião para o espaço público e quebrar paradigmas de invisibilidade e medo da intolerância, ou por todas essas características juntas. Os ancestrais são cultuados em memória de ações muito concretas, por seu modo de existir.

O parágrafo acima introduz uma chave de leitura para o que segue. Porque ao falarmos de acolhimento, assistência, cuidado, voluntariado, no que tange a um ethos afrorreligioso, não estamos lidando com aspectos morais, mas com uma ética com o mundo: em que é necessidade vital equilibrar as forças, entre aquilo que pegamos do mundo e aquilo que devolvemos a ele. Certa vez, ouvi de um amigo iniciado uma explicação que tentava dar conta dessa espécie de ordem dos fluxos de axé: "Ninguém dá o que não tem. Dar é um jeito de ter".

As casas de religiões de matrizes africanas visitadas no Mapeamento das Casas de Religião de Matrizes Africanas no Rio Grande do Sul (Módulo 2) - Pelotas, Rio Grande e Jaguarão compõem malhas de acolhimento e assistência de pessoas e grupos em condição social vulnerabilizada pelas mais diversas violências e desigualdades. Pelo que foi narrado pelos/as interlocutores/as da pesquisa, tal aspecto faz parte da constituição mesma da vida afrorreligiosa enquanto vida não desengajada da vida comunitária - e por que não planetária? - pois as noções de "vida boa" praticadas pelos terreiros não estão voltadas apenas para 
quem é de religião afro-brasileira. Um entre os muitos exemplos trazidos nessa pesquisa é o Projeto Ori, de reforço escolar e socialização de crianças e jovens, de diferentes regiões da cidade de Pelotas, desenvolvido no CBTT Caboclo Rompe Mato - Ilê Axé Xangô e Oxalá, de İyá Gisa De Oxalá:

İyá Gisa vai até as escolas, divulga o projeto, e os pais e/ou professores encaminham as crianças - já teve alunos do centro da cidade, do Fragata, do Navegantes, da Cohab, de todos os credos religiosos e oriundas de todos os tipos de instituições de ensino. Uma vez por semana, o projeto recebe a colaboração de uma psicóloga, que presta orientação às crianças. O Projeto Ori não tem finalidade religiosa, mas a ações assistenciais e comunitárias podem ser consideradas uma maneira de o axé da casa contribuir para melhorar a vida de outras pessoas, pois, segundo a ialorixá: "A nossa casa fica forte quando os membros desta casa, e adjacências, são fortes”. İyá Gisa, por isso, afirma que sua casa pode ser considerada um quilombo urbano (KOSBY; OLIVEIRA, 2021, p. 110).

A própria constituição de uma casa de religião pode ser vista como uma casa coletiva. Mãe Ema de Xangô, de Rio Grande, traz lembranças de seus antepassados religiosos:

A mãe de santo conta que, no tempo que Mãe Neli Da Oiá era viva, as mães de santo quando botavam os pais no chão, colocavam as crianças também (sem sangue na cabeça), para que elas fossem aprendendo, tomando gosto pela religião e não pela rua; aprendiam torrando milho, fazendo pequenas atividades, se ambientando com aquele universo. Segundo ela, "os pais de santo antigos" sempre tinham algum filho de santo que não tinha onde morar, ou tinham se desvinculado da família carnal, e que moravam no terreiro, em peças no pátio, contíguas à casa. Alguns pais de santo, criavam como netos, os filhos de suas filhas de santo - o que era bastante comum quando estas eram prostitutas. Ela enfatiza o fato de essas mulheres, no terreiro, serem respeitadas: "na rua, elas tinham nome de guerra, mas na casa do pai de santo, elas eram a Fulana, e a Fulana De Tal Santo, eram respeitadas". Conta que muitas saíram da vida de prostituição e se tornaram mães de santo. Para Mãe Ema, "a gente é como uma aldeia" ((KOSBY; OLIVEIRA, 2021, p. 175).

A essa noção de vida boa, em que para a casa estar bem a vida do entorno também deve estar, traz muitas semelhanças com a concepção de Buen Vivir fundamentada em cosmovisões dos povos e nacionalidades originários latino-americanos, e incorporada, inclusive, nos preceitos do chamado Novo Constitucionalismo da América Latina (ACOSTA, 2008). Segundo Acosta, dentre os preceitos que sustentam o conceito indígena de Buen Vivir está a ideia de uma vida harmônica:

Es decir equilibrada entre todos los individuos y las colectividades, con la sociedad y con la Naturaleza. No se puede olvidar que lo humano se realiza (o debe realizarse) en comunidad; con y en función de otros seres humanos, sin pretender dominar a la Naturaleza (ACOSTA, 2008, p. 5). 
Mãe Ema de Xangô traz ainda o significado de ser mãe de muita gente quando se é mãe de santo. Ela conta que atende pessoas que vão à sua casa só para conversar, pedir conselhos, gente que perdeu a mãe cedo e que ficou sem referência. Ela reforça a importância de receber as crianças do bairro, mesmo que seja só para ganharem uns docinhos, pois o terreiro é uma referência de acolhimento para quem se vê solitário ou precisando de uma palavra de conforto, de uma orientação. Em bairros em que a criminalidade acaba sendo o destino de muitos jovens, como é o de Mãe Ema, a casa de religião pode ser um lugar onde se conhece pessoas de diferentes lugares, se faz relações de amizade, de trabalho, de parceria.

Todas as casas visitadas fazem algum tipo de atendimento espiritual gratuito para pessoas de fora do terreiro. Pai Chiquito, por exemplo, uma vez por semana faz passes e benzeduras, pelo lado da Umbanda; neste dia, a casa chega a receber entre 60 e 70 pessoas, vindas de toda a cidade e municípios vizinhos. O babalorixá conta que é chamado na vizinhança até para ajudar no auxílio a idosos, fazer injeções, medicações.

A maioria das casas exerce alguma atividade assistencial, como arrecadar agasalhos e alimentos para distribuir a grupos mais vulnerabilizados de suas comunidades. É bastante comum que os terreiros distribuam as carnes dos animais sacralizados para os vizinhos que tem dificuldade de comprar alimentos. Algumas mães de santo, como Mãe Nara do Xapanã, fazem refeições comunitárias para doação com essas carnes.

Além disso, quando conhecemos as trajetórias de alguns de nossos interlocutores e de seus antepassados, percebemos que muitos deles/as foram primeiramente acolhidos nas casas onde se iniciaram, seja por serem homossexuais, transexuais, seja por serem mães divorciadas e/ou desempregadas etc. $\mathrm{O}$ que se nota é que as casas de religiões de matrizes africanas têm um valor comunitário, mesmo para quem não é iniciado. Foram frequentes as vezes em que, durante a realização das entrevistas desta pesquisa, interrompemos o procedimento para que nossas interlocutoras atendessem vizinhos, que pediam o acendimento de velas ou a energização de roupas de pessoas que estavam doentes ou desempregadas.

Temos, assim, que as casas de religiões de matriz africana trazem em seus fundamentos cosmoecológicos e religiosos premissas que, ao ressoar $^{7}$ no discurso das ciências humanas a respeito das crises do capitalismo individualista e exploratório, que tão fortemente tem marcado o Antropoceno, este "tempo de catástrofes" - discursos tais como, por exemplo, o que traz a necessária afirmação de que "a pandemia é sintoma de uma catástrofe muito maior" (SEGATA, 2021) - radicalizam-no, permitindo que possamos enxergar em um dos lados da doença o seu antídoto: a retomada dos laços que compõem uma vida boa. 


\section{NOTAS}

1. A realização do Mapeamento das Casas de Religião de Matrizes Africanas no Rio Grande do Sul (Módulo 2) - Pelotas, Rio Grande e Jaguarão segue as diretrizes do Projeto Básico do IPHAN-RS, visando produzir material técnico especializado a respeito do campo afrorreligioso do sítio a que se refere, para subsidiar futuras ações de patrimonialização. O Mapeamento foi executado pela empresa de consultoria Campo - Cultura, Ambiente e Patrimônio (Belo Horizonte-MG), tendo como equipe os seguintes pesquisadores: Marília F. Kosby (antropóloga - coordenadora da pesquisa), Vinícius Pereira de Oliveira (historiador - responsável pela pesquisa historiográfica), Nelson Luís Corrêa (pesquisador local, Jaguarão-RS), Marcelo Studinski (pesquisador local, Rio Grande-RS).

2. Para Descola $(1996,2005)$, a consolidação do paradigma cosmológico naturalista ocidental se dá no período entre 1500 e 1800, pautado pelas "revoluções" cosmológicas promovidas pelas ciências naturais. No que diz respeito às relações entre humanos e seres da natureza, esse paradigma oscila entre uma matriz focada no "predatismo" predominante (expressa na exploração crescente dos recursos naturais) e algumas variações de "reciprocidade" e "protecionismo" (presentes nos movimentos conservacionistas e de defesa animal). De qualquer forma, as separações ontológicas natureza/cultura, humano/não humano, humanidade/animalidade, são reforçadas e reproduzidas pelo naturalismo em todas as suas versões (KOSBY, 2017).

3. A potência Gaia, trazida por Stengers, é uma noção cientificamente construída por Lovelock e Margulis, nos anos 1970, inspirada no mito grego homônimo. Na versão de Hesíodo da mitologia grega, Gaia (a terra) tem filhos com Urano (céu). São filhos de três tipos: ciclopes, titãs e hecatônquiros. Dos segundos descenderão os deuses e semideuses que comporão o panteão olímpico. A autora escolhe manter este nome Gaia para, segundo ela, resistir à oposição brutal entre saberes científico e não científicos, já que os autores dessa teoria foram acusados preconceituosamente de animismo e antropomorfismo, por evocarem um ser que aparece em narrativas mitológicas.

4. Colóquio Internacional "Os mil nomes de Gaia: do Antropoceno à Idade da Terra”, promovido pelo Departamento de Filosofia da PUC-Rio e pelo PPGAS do Museu Nacional - UFRJ, realizado entre 15 e 19 de setembro de 2014.

5. O depoimento de İyá Gisa nesse sentido faz-se de suma importância para a pluralização dos discursos acerca dos bens culturais e paisagísticos já patrimonializados em Pelotas. O exemplo do arroio Pelotas pode ser associado ao tombamento da antiga Charqueada São João, pelo critério arquitetônico de seu período de construção, sendo sua apropriação turística focada principalmente nos elementos estéticos e culturais que reforçam as narrativas das elites ou da "história oficial".

6. A narrativa de Mãe Michele nos reporta ao conceito de sindemia, tal como abordado por Singer e Rilko-Bauer (2021, p. 8): “... interação sinérgica adversa de duas ou mais doenças ou outras condições de saúde (por exemplo, dieta nutricionalmente inadequada) promovida ou facilitada por condições sociais e ambientais" - tradução minha.

7. Segundo Anjos (2006, p. 120): "Quando falo em filosofia política da religiosidade afro-brasileira, trata-se de deslocar a vantagem estratégica do antropólogo 
sobre o discurso do nativo de modo a fazer com que este último funcione dentro do texto antropológico. É a esse funcionamento que, evocando um termo caro a Deluze e Guattari (1980), se poderia chamar de ressonância da filosofia política afro-brasileira no interior da antropologia."

\section{REFERÊNCIAS}

ACOSTA, Alberto. El Buen Vivir, una oportunidad por construir. Revista Ecuador Debate, Quito, n. 75, dic. 2008.

ANJOS, José Carlos G. dos. No território da linha-cruzada: a cosmopolítica afro-brasileira. Porto Alegre: Ed. UFRGS, 2006.

BARBOSA NETO, Edgar R. A Máquina do mundo: variações sobre o Politeísmo em coletivos afro-brasileiros. Tese (Doutorado) - Programa de Pós-Graduação em Antropologia Social do Museu Nacional da Universidade Federal do Rio de Janeiro, Rio de Janeiro, 2012.

CAMPOS, Isabel Soares. Os prazeres do balneário: sob as bênçãos de Iemanjá. Religiões afro-brasileiras e espaço público em Pelotas. Dissertação (Mestrado em Antropologia) - Programa de Pós-Graduação em Antropologia da Universidade Federal de Pelotas, Pelotas, 2015.

DESCOLA, Philippe. Constructing Natures. In: DESCOLA, Philippe. Nature and Society: Anthropological perspectives. London: Routledge, 1996.

DESCOLA, Philippe. Par de-là nature et culture. Paris: Gallimard, 2005. DESPRET, Vinciane. "O que diriam os animais se...?”. Trad. Cícero de Oliveira. Belo Horizonte: Chão da Feira, 2016.

INGOLD, Tim. Chega de etnografia! A educação da atenção como propósito da antropologia. Educação, Porto Alegre, v. 39, n. 3, p. 404411, set./dez. 2016.

KOSBY, Marília F. "Se eu morrer hoje, amanhã eu melhoro": sobre afecção na etnografia dos processos de feitura da pessoa de religião no Batuque, em Pelotas-RS. Dissertação (Mestrado em Ciências Sociais) - Universidade Federal de Pelotas, Pelotas, 2009.

KOSBY, Marília F. Alma-caroço: peregrinações com cabras negras pelo extremo sul do Brasil. Tese (Doutorado) - Programa de Pós-graduação em Antropologia Social, Porto Alegre, UFGRS, 2017.

KOSBY, Marília F. Trilhas de sangue e mel: esboço peregrino de uma cosmoecologia negra no sul do Brasil. Etnográfica, Lisboa, v. 25, n. 2, 2021.

KOSBY, Marília; OLIVEIRA, Vinícius P. de. Mapeamento das casas de religião de Matrizes africanas no Rio Grande do Sul: Módulo 2 - Pelotas, Rio Grande e Jaguarão (Relatório Final). Porto Alegre: Instituto do patrimônio Histórico e Artístico Nacional, 2021.

MINISTÉRIO DO TURISMO. Projeto básico. Mapeamento das Casas de Religião de Matriz Africana no Rio Grande do Sul - Módulo 2: Pelotas, Rio Grande e Jaguarão. IPHAN, 2020. Disponível em: <https:// 
sei.iphan.gov.br/sei/modulos/pesquisa/md_pesq_documento_consulta_externa.php?9LibXMqGnN7gSpLFOOgUQFziRouBJ5VnVL5b7UrE5TdmAoUke9LflBkDLzrofi5wLukcUjFAU2P6h_g8P0Ofq3guN543cSyGxl2EDBoFFALeNakrvBGmEJe8ZK6fBOt>. Acesso em: 15 nov. 2021.

PRANDI, Reginaldo. Mitologia dos Orixás. São Paulo: Companhia das Letras, 2001.

SEGATA, Jean. Covid-19: escalas da pandemia e escalas da antropologia. Boletim Especial, n. 2, 23 mar. 2020. Disponível em: <http:// anpocs.org/index.php/publicacoes-sp-2056165036/boletim-cientistas-sociais/2307-boletim-n-1-cientistas-sociais-o-o-coronavirus-2>. Acesso em: 06 set. 2021.

SEGATA, Jean. "A pandemia é sintoma de uma catástrofe muito mais ampla". Entrevista a João Paulo Charleaux. Nexo, 06 set. 2021. Disponível em: <https://www.nexojornal.com.br/entrevista/2021/09/06/\%E2\%80\%98A-pandemia-\%C3\%A9-sintoma-de-uma-cat\%C3\%A1 strofe-muito-mais-ampla\%E2\%80\%99>. Acesso em: 07 set. 2021.

SINGER, Meryll; RYLKO-BAUER, Barbara. The syndemics and structural violence of the covid pandemic: anthropological insights on a crisis. Open Anthropological Research, n. 1, p. 7-32, 2021.

STENGERS, Isabelle. No tempo das catástrofes: resistir à barbárie que se aproxima. Trad. Eloisa Araujo Ribeiro. São Paulo: Cosac Naify, 2015. PRADO FILHO, Kleber; TETI, Marcela M. A cartografia como método para as ciências humanas e sociais. Barbarói, Santa Cruz do Sul, n. 38, p. 45-59, jan./jun. 2013. 